\title{
Ó MON PETIT MARCEL QUATRO POEMAS BRASILEIROS SOBRE PROUST
}

\author{
MAURO, Fillipe ${ }^{1}$
}

\begin{abstract}
RESUMO: Em 1920, Paul Morand publicou uma controversa ode ao amigo Marcel Proust. Apesar de sua grande musicalidade e da sofisticação de suas rimas internas, o poema foi visto pelo autor da Recherche como uma caricatura de mal gosto de sua vida privada. Ele jamais poderia saber, mas vários poetas brasileiros seguiram os mesmos passos de Morand e escreveram poemas em sua homenagem. Augusto Meyer descreveu uma experiência de leitura da Recherche nos pampas gaúchos; Jorge de Lima lamentou que Proust não tenha conhecido o sertão nordestino; João Cabral de Melo Neto resumiu, na austeridade de sua poesia do menos, a intrincada feitura do romance; e Cláudio Murilo Leal, em versos que lembram Drummond, disse como Proust marcou a vida de seu eu-lírico e determinou sua formação estética. A partir de uma leitura comparada desses quatro poemas, buscaremos demonstrar como a ressonância de À la recherche du temps perdu na moderna literatura brasileira não se limitou ao gênero romanesco, manifestou-se também na lírica e se fez presente nas mais variadas (e por vezes antagônicas) correntes de pensamento artístico.
\end{abstract}

PALAVRAS-CHAVE: Marcel Proust; Paul Morand; Augusto Meyer; Jorge de Lima; João Cabral de Melo Neto; Cláudio Murilo Leal.

\section{Ó MON PETIT MARCEL QUATRE POÈMES BRÉSILIENS SUR PROUST}

RÉSUMÉ : En 1920, Paul Morand a publié une ode controversée à son ami Marcel Proust. Malgré sa grande musicalité et la sophistication de ses rimes internes, le poème a été vu par l'auteur de la Recherche comme une caricature de mauvais goût de sa vie privée. Il n'aurait jamais pu l'imaginer, mais plusieurs poètes brésiliens ont suivi le même chemin que Morand et ont aussi écrit des poèmes à

\footnotetext{
${ }^{1}$ Doutorando do Departamento de Letras Modernas da Universidade de São Paulo e do CERC - Centro de Estudos e de Pesquisas Comparatistas da Universidade Paris III - Sorbonne Nouvelle. Nota: as citações de À la recherche du temps perdu (RTP) foram extraídas da edição em quatro volumes da Bibliothèque de la Pléiade, organizada por Jean-Yves Tadié; aquelas de Contre Sainte-Beuve são originárias da edição da Bibliothèque de la Pléiade organizada por Pierre Clarac en 1971 (CSB); e todas as menções à correspondência de Proust (Corr.) provêm da coleção em 21 volumes, organizada por Philip Kolb entre 1970 e 1993. O autor agradece o apoio da FAPESP Fundação de Amparo à Pesquisa do Estado de São Paulo. fillipe.mauro@sorbonne-nouvelle.fr.
} 


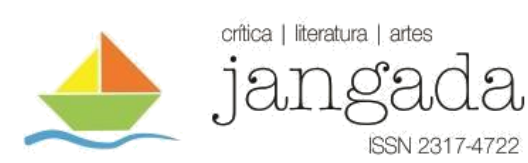

son hommage. Augusto Meyer a décrit une expérience de lecture de la Recherche dans les pampas gauchos ; Jorge de Lima a regretté le fait que Proust n'ait jamais visité la région du sertão, dans le nordest brésilien ; João Cabral de Melo Neto a résumé, avec l'austérité de sa poesia do menos, l'élaboration complexe du roman ; et Cláudio Murilo Leal, dans des vers similaires à ceux de Drummond, a raconté comment Proust a marqué la vie de son je lyrique et a déterminé sa formation esthétique. À partir d'une lecture comparée de ces quatre poèmes, nous avons cherché à démontrer que la résonance de la Recherche au sein de la littérature brésilienne moderne ne s'est pas bornée au genre romanesque, qu'elle s'est manifestée aussi dans la poésie et était présente dans les courants les plus variés (et parfois antagonistes) de la pensée artistique.

MOTS-CLÉS : Marcel Proust; Paul Morand; Augusto Meyer, Jorge de Lima; João Cabral de Melo Neto; Cláudio Murilo Leal.

Os leitores de Proust já conhecem há bastante tempo a história de sua amizade com o poeta Paul Morand. Jovem diplomata, adido à embaixada francesa em Londres, ele ouviu falar de $D u$ côté de chez Swann pela primeira vez no outono de 1914, através do colega Bertrand de Fénelon. O livro lhe causou grande impressão e as palavras lisonjeiras de que seu estilo era "extremamente mais forte que Flaubert" não tardaram a chegar aos ouvidos de Proust. Após alguns desencontros (ou Proust estava doente, ou Morand partia em viagem), os dois enfim se conheceram no outono de 1915. De passagem por Paris, Morand se hospedou no apartamento de Henri Bardac, onde o notívago Proust soou a campainha por volta das onze e meia da noite, surpreendendo a todos de pijamas. Daí o título de Le visiteur du soir, importante volume de memórias de Morand sobre sua relação com o autor da Recherche.

Nos dias seguintes, em carta a Antoine Bibesco, Proust se disse "muito feliz" (Corr., XIV, p. 221) por ter conhecido o poeta, em quem reconheceu "um grande futuro" (TADIÉ, II, p. 292). Os principais biógrafos de Proust o descrevem como um "belo homem, viril, que 'atrai todos os corações para si', o tipo que agrada Marcel” (TADIÉ, II, p. 292). O tempo os aproximou, as cartas se multiplicaram e os encontros, cada vez mais frequentes, produziram em Proust uma atração platônica: “eu gosto cada vez mais dele” (Corr. XVII, p. 415).

Quando Morand é nomeado secretário no Palazzo Farnese e parte para Roma, Proust escreve lamuriante: "não consigo ser estoico ao ponto de ignorar que Paul Morand entrou para minha vida e que ele a deixa antes que termine" (Corr. XVI, p. 274). Poucas semanas depois, em nova carta, extravasa as saudades do amigo: "não consigo entender como é possível que seu 
rosto seja tão continuamente presente para mim, que eu me lembre dos mínimos trejeitos do seu sorriso, da simplicidade que envolvia sua bondade" (Corr. XVI, p. 370).

A atração de Proust é tamanha que ele repete com o casal Paul Morand e Hélène Chrisoveloni, princesa de Soutzo, os triângulos que já havia formado, mais jovem, com Albufera e Louisa de Mornand ou com Gaston de Caillavet e Jeanne Pouquet. Um triângulo contra o qual Morand se insurgiu, em que "o amante se faz de confidente" e "o objeto amado não é aquele que pensamos", onde se "ama um homem dando a aparência de se amar uma mulher" e "se disputa uma mulher com o homem que se ama" (TADIÉ, I, p. 192-193).

Dessa amizade "difícil, complicada", como "foram provavelmente todas as amizades de Proust" (COMPAGNON, p. 248), floresceu um famoso poema no qual Morand presta uma homenagem ao autor da Recherche. Os versos se chamam Ode à Marcel Proust e foram publicados em 1920 na pequena coletânea Lampes à arc:

\section{Ode à Marcel Proust}

\section{Ombre}

née de la fumée de vos fumigations, le visage et la voix mangés par l'usage de la nuit, Céleste, avec sa rigueur, douce, me trempe dans le jus noir de votre chambre qui sent le bouchon tiède et la cheminée morte.

Derrière l'écran des cahiers, sous la lampe blonde et poisseuse comme une confiture, votre visage gît sous un traversin de craie.

Vous me tendez des mains gantées de filoselle; silencieusement votre barbe repousse au fond de vos joues.

Je dis :

— Vous avez l'air d'aller fort bien.

Vous répondez:

— Cher ami, j'ai failli mourir trois fois dans la journée.

Vos fenêtres à tout jamais fermées vous refusent au boulevard Haussmann rempli à pleins bords, comme une auge brillante, 
du fracas de tôle des tramways.

Peut-être n'avez-vous jamais vu le soleil ?

Mais vous l'avez reconstitué, comme Lemoine, si véridique,

que vos arbres fruitiers dans la nuit

ont donné leurs fleurs.

Votre nuit n'est pas notre nuit :

C'est plein des lueurs blanches

des catléyas et des robes d'Odette,

cristaux des flûtes, des lustres

et des jabots tuyautés du Général de Froberville.

Votre voix, blanche aussi, trace une phrase si longue

qu'on dirait qu'elle plie, alors que comme un malade

sommeillant qui se plaint,

vous dites : qu'on vous a fait un énorme chagrin.

Proust, à quels raouts allez-vous donc la nuit

pour en revenir avec des yeux si las et si lucides?

Quelles frayeurs à nous interdites avez-vous connues

pour en revenir si indulgent et si bon?

et sachant les travaux des âmes

et ce qui se passe dans les maisons,

et que l'amour fait si mal?

Étaient-ce de si terribles veilles que vous y laissâtes

cette rose fraîcheur

du portrait de Jacques Émile-Blanche?

et que vous voici, ce soir,

pétri de la pâleur docile des cires

mais heureux que l'on croie à votre agonie douce

de dandy gris perle et noir ? ${ }^{2}$

(MORAND, 1920, p. 17-19)

2 "Ode a Marcel Proust: Sombra / nascida da fumaça de tuas fumigações, / rosto e voz / comidos / pelo uso da noite, / Celeste, / com seu rigor, doce, mergulha-me no sumo negro / de teu quarto / que cheira a cortiça morna e a lareira apagada. / Por trás do anteparo dos cadernos, / sob a lâmpada loura e pegajosa como um doce, / jaz teu rosto no travesseiro de giz. / Tu me estendes mãos enluvadas em filosela; / silenciosamente brota tua barba / no fundo das faces. / Digo: - Parece que vais otimamente. / Respondes: / - Meu caro, estive a ponto de morrer, três vezes, durante o dia. / Tuas janelas, para todo o sempre fechadas, / recusam-te ao boulevard Haussmann / cheio até a borda, / como uma pia brilhante, / do fragor metálico dos bondes. / Acaso terás visto algum dia o sol? / Mas tu o reconstituiste, como Lemoine, tão verídico, / que tuas árvores frutíferas à noite / floresceram. / E tua noite não é a nossa noite: / Está cheia do branco vislumbre / de catléias, vestidos de Odete, / cristais de flautas, lustres / e folhos encanudados do General de Froberville. / Tua voz, branca também, traça uma frase tão longa / que se diria dobrar-se, quando, como um doente / a lastimar-se, cochilando, / dizes: que te causaram um enorme desgôsto. / Proust, a que reuniões vais, afinal, à noite, / para voltares com olhos tão lassos e tão lúcidos? / Que pavores, a nós interditos, conheceste / para voltares tão indulgente e bom? / e sabendo os trabalhos das almas, / o que se passa nas casas, / e que o amor faz tanto mal? / Seriam assim terríveis essas vigílias, para que nelas deixasses / aquêle róseo frescor / do retrato de Jacques Emile-Blanche? / e para estares aqui, esta noite, / modelado na palidez dócil da cêra, / mas feliz por acreditarmos em tua agonia / de dandy cinza pérola e negro?" (MORAND, 1948, p. 5-6, tradução de Carlos Drummond de Andrade). 


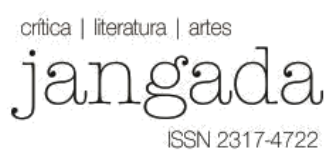

De seu gênero, a ode de Morand apresenta apenas a musicalidade e o tema heroico. $\mathrm{O}$ que não significa de modo algum o prejuízo de sua qualidade estética. Bem ao contrário, a submersão da regularidade do canto clássico a estrofes heterogêneas, a versos livres modernos e a rimas internas intercaladas serve a um notável efeito expressivo: tudo é interior nesse poema; nada é relegado às suas margens, à sua superfície.

No segundo verso da primeira estrofe, fumée enlaça simultaneamente o particípio née e o substantivo fumigations, operando como uma palavra de transição entre dois regimes sonoros distintos. No primeiro verso da segunda estrofe, o poeta se vale de écran para migrar do gutural derrière rumo ao nasal cahiers. Mais adiante, no verso 13 da quarta estrofe, a hesitação entre dois complementos nominais se reflete em uma rica oscilação sonora, os lustres que combinam o acento em $r$ de cristaux com o acento em $l$ de flûtes. O pronome leurs, no nono verso da quarta estrofe, é recuperado duas linhas abaixo no substantivo lueurs. Uma das raríssimas rimas externas se dá entre o adjetivo fermées e o substantivo tramways - mas mesmo ela é discreta e distante, separada por dois versos, e depende de um galicismo aproximativo do inglês. Surgem, assim, imagens matizadas e fluidas, de grande impressionismo, onde os opostos se harmonizam, as fronteiras são suprimidas - onde o sol e as árvores frutíferas se confundem com a escuridão de janelas sempre fechadas e um sumo negro.

A musicalidade introspectiva desses versos é um reflexo formal da própria visão do herói louvado. Nessa ode, não estamos diante da grandiosidade do herói histórico das epopeias. Surge, na realidade, esse herói-escritor que, de modo indeterminado e nebuloso, consegue reconstituir do interior de sua clausura uma vida verdadeira. Esse herói-escritor, muito mais frágil, que privilegia o interior ao exterior, o subjetivo ao objetivo e que se esforça para "se despojar, diante da realidade, de todas as noções de sua inteligência" (RTP, II, p. 196). Esse é o seu feito lendário e maravilhoso, que justifica o canto.

Os versos livres e as rimas internas da ode de Morand não são, assim, apenas um arroubo de modernismo. Eles se libertam da norma clássica justamente para incorporar aquilo que o poeta compreende como sendo as inovações estilísticas de seu próprio herói-escritor. A homenagem não está apenas em cantar Proust, mas, antes, em cantar como Proust. O verso 34, em que o poeta alude às frases tão longas da Recherche, é ele mesmo parte de um quarteto profundamente subordinado, que se origina em uma realidade complexa e específica para culminar em um dado mais aparente e geral, isolado por dois pontos. O verso de Morand se dobra justamente para melhor refletir - e elogiar - o aspecto entrecortado das frases de Proust. 


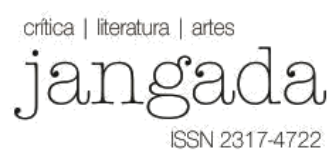

Tadié disse que o estilo desse poeta era marcado por "agilidade, emoções bruscas, mundanas e breves, pelo retorno ao classicismo da escrita", sem contar a "sobriedade, a geometria, a superfície ornada com alguns toques dourados" (TADIÉ, II, p. 283). Se isso for verdade, a Ode à Marcel Proust constitui uma exceção à regra. Pois, para louvar a literatura de Proust, o poeta abdica de toda agilidade, de toda brevidade e solapa toda a geometria da ode clássica. Restam as filigranas douradas. Mas elas não são apenas um detalhe esparso. Morand prefere prolongar ao máximo seus versos (ou, às vezes, reduzi-los a uma ínfima palavra) para incrementar o valor de cada um dos seus termos, para atribuir-lhes uma "preciosa matéria", pintá-los com "várias camadas de cor" e tornar suas frases "em si mesmas algo precioso" (RTP, III, p. 692).

Proust não reagiu com nenhum entusiasmo ao poema e o considerou uma caricatura indelicada e deselegante de sua vida privada. Em uma carta de 10 de outubro de 1919 a Paul Morand, ele exprimiu toda sua indignação. Reconheceu - não sem ironia - que o poema é "muito belo" e chamou Morand de "Walt Whitman de nosso tempo e de nosso país" (Corr. XVIII, p. 423). Garante que jamais se oporia à redação da ode, mas diz que a ousadia de a publicar fere um amigo "desarmado por sua própria ternura" (Corr. XVIII, p. 422). Segundo Proust, o verso em que Morand trata de "pavores, a nós interditos" deixa a impressão de que ele havia sido "pego em um arrastão ou largado morto por bandidos" (Corr. XVIII, p. 422). A descrição de seu físico pálido expõe "esse horror de meu retrato cuja barba cresce" (Corr. XVIII, p. 423). Onde o poema se pergunta "a que reuniões vais, afinal, à noite, para voltares com olhos tão lassos e tão lúcidos?", o biógrafo George Painter viu ainda a prova de que "Morand evidentemente tinha alguma suspeita das visitas de seu amigo ao bordel de Albert [Le Cuziat]" (PAINTER, II, p. 306).

Mas o mais interessante são os argumentos propriamente literários dessa indignação. Em sua resposta a Morand, Proust recupera uma das discussões mais importantes de $\grave{A}$ la recherche du temps perdu, que é a crítica da inteligência e a apologia da metáfora e das impressões verdadeiras: "caro amigo, você é inteligente demais para não perceber que isso aí [a ode] é simplesmente uma notação" (Corr. XVIII, p. 423). Ao se limitar à biografia do autor, aos seus costumes, à sua moral, Morand teria incorrido no mesmo equívoco de Sainte-Beuve, qual seja, o de "não separar o homem e a obra" (CSB, p. 221).

O problema desse método, que consiste em "munir-se de todas as informações possíveis sobre um escritor, cotejar sua correspondência, interrogar as pessoas que o conheceram", é que ele "desconhece aquilo que uma convivência um pouco profunda com nós Jangada| ano 9, nr. 17, jan/jun, 2021 | ISSN 2317-4722 


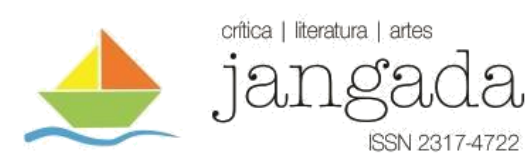

mesmos nos revela: que um livro é o produto de um outro eu e não daquele que manifestamos em nossos hábitos, na sociedade, com nossos vícios" (CSB, p. 221). Por essa razão é que Proust, cada vez mais "atribui menos valor à inteligência" e percebe com maior clareza que "somente fora dela o escritor é capaz de recuperar algo de nossas impressões, isto é, alcançar algo de si mesmo e a matéria única da arte" (CSB, p. 211). Para realmente falar como Proust, Morand deveria ter "deixado falar o inconsciente" e não "apenas anotar com os olhos" (Corr. XVIII, p. 423).

A despeito de algumas alfinetadas esporádicas, o entrevero se apaziguou e a amizade com Morand sobreviveu à ode. Somente Proust não poderia jamais imaginar que - consciente ou inconscientemente, pouco importa - vários outros poetas, pertencentes a um contexto histórico distinto e a uma geografia longínqua, também seguiriam os passos de Morand nos anos seguintes e se valeriam dos mais diversos tipos de lírica para homenageá-lo. O Brasil, esse distante país que "já foi solo fértil para estudos proustianos", cujos "maiores críticos escreviam sobre Proust", que publicou vários romances fertilizados pela Recherche, que já acumula três traduções rigorosas dessa obra e que contou até mesmo com um Proust-Clube sediado na praia de Copacabana, também produziu uma pequena fortuna poética em tributo à busca do tempo perdido (GALVÃO, p. 11-12; SAUTHIER, p. 27).

O primeiro desses poemas brasileiros em homenagem a Proust floresceu nos pampas e vem da pena de Augusto Meyer. Esse modernista gaúcho é conhecido por aludir a Proust em dois romances memorialistas - Segredos da infância (1949) e No tempo da flor (1966) - e também por ter sido o autor de um pequeno glossário que acompanhou a primeira tradução de Du côté de chez Swann em língua portuguesa no ano de 1948. Mas bem antes disso, já em 1928, o jovem poeta incluiu na antologia Giraluz uma interessante Elegia para Marcel Proust onde a alcova e o fantasma descrito por Morand se colorem com temas tropicais.

\title{
Elegia para Marcel Proust
}

\author{
Aléa de bambús, verde ogiva \\ recortada no azul da tarde mansa, \\ o ouro do sol treme na areia da alameda, \\ farfalham folhas, borboletas florescem. \\ Portão de sombra em plena luz. \\ Gemem as lizas taquaras como frautas folhudas \\ onde o vento imita o mar. \\ Marcel, menino mimoso, estou comtigo, Proust:
}

Jangada | ano 9, nr. 17, jan/jun, 2021 | ISSN 2317-4722 
vejo melhor a amêndoa negra dos teus olhos.

Transparencia de uma longa vigília, imagino as tuas mãos

como dois passaros pousados na penumbra.

Escuta — a vida avança avança e morre...

Prender a onda que franjava a areia loura de Balbec?

Setim roseo das macieiras no azul.

Flora carnal das raparigas passeando á beira-mar.

Bruma esfuminho Paris pela vidraça

Intermittencias chuva e sol LE TEMPS PERDU.

Marcel Proust, diagramma vivo sepultado na alcova, o teu quarto era maior que o mundo:

cabia nelle outro mundo...

Fecho o teu livro doloroso nesta calma tropical como quem fecha leve a aza de um cortinado nina-nana sobre o somno de um menino...

(MEYER, 1928, p. 40-41)

Não é apenas a imagem mórbida de um "diagramma vivo sepultado na alcova" que lembra a ode de Morand na elegia de Meyer. Há uma série de semelhanças formais que chamam grande atenção.

Antes de tudo, uma vez mais o leitor se vê diante de um texto moderno que recupera um tom específico da tradição clássica subvertendo suas normas de composição. Em Morand, os versos livres e a heterogeneidade das estrofes compunham uma ode de feitos heroicos; em Meyer, a mesma composição irregular serve às lamúrias de uma elegia, na qual o leitor vive as dores do livro amado em meio à solidão bucólica de uma "calma tropical".

Em seguida, a opção por rimas internas se repete, no mesmo intuito de produzir um efeito expressivo impressionista, matizado e fluido, onde distintos elementos, por vezes até mesmo contrastantes, parecem se harmonizar segundo os influxos mentais do eu-lírico. Antonio Candido já havia mencionado esse "gosto finíssimo" de Meyer (2010, p. 97). São versos como "farfalham folhas, borboletas florescem", em que a rica interposição de fonemas em $f, r, l$ e $s$ exprime um vivo movimento orgânico e vegetal. Ou ainda "gemem as lizas taquaras como frautas folhudas", onde os mesmos sons - agora reorganizados, com o alinhamento dos fonemas em $s$ ao final da maior parte dos termos - evocam o sopro contínuo do vento.

Mas Meyer não mobiliza todos esses recursos expressivos sob uma perspectiva biográfica. A ausência do dado característico, a alienação das imagens morais cede espaço a um interessante método criativo. Como o poeta nunca penetrou o escuro quarto da rue Hamelin, 


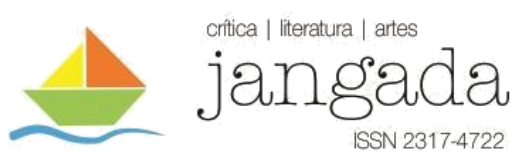

nunca cerrou as mãos de Céleste Albaret, não pode, enfim, falar quem era o autor, quais eram seus hábitos, como era sua aparência física, vê-se compelido a cantar não um homem, mas uma preciosa experiência de leitura, que é o único material que tem à disposição.

O Proust de Meyer é, antes de mais nada, um ser lido e imaginado. No importante verso "Marcel, menino mimoso, estou comtigo, Proust", a fratura do nome próprio e o enxerto de uma nova oração provoca ambiguidades significativas. Não sabemos ao certo se o aposto "menino mimoso" qualifica Marcel ou o sujeito oculto do eu-lírico, pois os dois seres se sobrepõem. Toda a representação de Proust se subordina aqui a elementos da memória e da consciência do próprio eu-lírico. A areia de Balbec confunde-se com a areia de alamedas de sua região; as róseas macieiras normandas se alternam com as aleias de bambus e as taquaras do sul; a bruma de Paris se contrapõe ao azul de uma tarde mansa. O poema se articula essencialmente em torno de "intermittencias", como ele próprio diz, de modo que o eu-lírico canta o autor amado cantando a si próprio, e vice-versa.

Mesmo quando o eu-lírico menciona a "amêndoa negra" dos olhos de Proust, ele o faz para sinalizar que agora, ao absorver sua leitura, ao enxergar sob suas lentes, o compreende melhor e mais profundamente. Tania Franco Carvalhal disse, a respeito desse poema, que Meyer está "em diálogo" com Proust e "associa sua experiência de poeta àquela do romancista" (p. 102). De fato, estamos diante de mais que uma mera aclimatação, uma simples troca de temas da Recherche. Meyer elaborou em seu poema aquilo que Proust recomendara a Morand. Ele abdicou das simples notações (às quais, por sinal, jamais poderia ter tido acesso) em favor de impressões mais verdadeiras suscitadas pela leitura do romance.A ode de Morand é a história de uma visita; a elegia de Meyer é a história de uma leitura. Proust e seu narrador são apenas o meio para que a consciência do eu-lírico se exprima. A grande exceção são os estereótipos soturnos da oitava estrofe, contra os quais Proust certamente se insurgiria. Mas é importante notar que até eles servem ao argumento de que o elogio a Proust depende de uma dimensão mais alargada e menos objetiva da realidade, a dimensão do altissonante "TEMPS PERDU”, onde cabem "outros mundos". Inclusive o mundo do eu-lírico e de sua vida nos pampas gaúchos, cujo símbolo maior, isolado por uma estrofe de um único verso, é o "portão de sombra em plena luz".

Em 1932, Jorge de Lima, autor do controverso ensaio Proust e do romance A Mulher obscura - que o crítico Ruy Coelho, aliás, chamava de verdadeiro "pastiche de Proust" (SAUTHIER, p. 284) -, incluiu um Poema a Marcel Proust em seus Poemas escolhidos. 


\section{Poema a Marcel Proust}

Ó mon petit Proust,

hoje o teu rosto de lua,

dêsse quadro bonito de Jacques Emile Blanche;

o teu rosto de flor noturna

se apagou, mon petit,

e

dentro de mim voltou,

o sertão, o sertão, o sertão,

pois,

mon petit, no meu país

as polícias passaram

e Lampião ficou;

os governadores passaram,

os congressos, os chefes políticos,

os exércitos,

as repúblicas,

as revoluções,

os grandes generais passaram

e Lampião ficou.

A nova poesia brasileira passou

e Lampião ficou

iluminando tudo

mais que teu rosto de lua

que Jacques Emile Blanche compôs.

É preciso ver:

Lampião é eterno

e é preciso crer na

opinião da Europa: Lampião

tira dos ricos para dar aos pobres.

É preciso crer nas orações fortes,

é preciso crer em Lampião.

Mon petit Proust, -

sai do teu salão,

vem ver o meu luar:

não há no mundo

luar como êste do sertão.

(LIMA, 1958, p. 337)

Se levarmos em conta a alusão à morte de Proust ao longo dos cinco primeiros versos, é possível que o poema de Jorge de Lima seja até mesmo anterior à elegia de Meyer. O que não causaria espanto algum, haja vista que Lima, assim como José Nava, irmão do autor de Baú de 


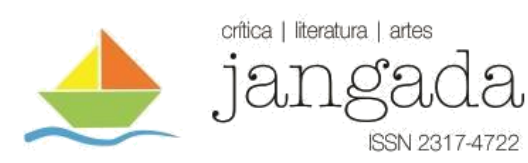

ossos, pertence ao grupo de escritores e intelectuais que reivindicaram para si a descoberta de À la recherche du temps perdu no Brasil.

Diz a crônica que Henri Rochat, mordomo do Ritz sustentado por Proust durante dois anos e um dos modelos possíveis para o personagem de Morel (TADIÉ, II, p. 336), teria aportado em Recife com alguns volumes da Recherche. O fugitivo, no entanto, deixou a bagagem como caução da hospedagem. A proprietária da pensão os entregou a um piloto da antiga companhia Latécoère que, por sua vez, decolou para Maceió. Lá, se consultou com o médico Jorge de Lima e o presenteou com os volumes. Lima ainda enviaria um deles ao Rio de Janeiro, para o crítico Alceu Amoroso Lima, que décadas depois escreveria a Suzy ManteProust, sobrinha de Marcel, perguntando por mais informações sobre um certo Rochas (sic). Tadeu Rocha registrou essa grande ciranda nos anos 60 (p. 49-56) e, mais recentemente, Étienne Sauthier a recuperou com grande minúcia, ressaltando o papel importante que o acaso e os acidentes desempenham na história da circulação internacional de textos e de ideias (p. 99-100).

Muito mais que o tema tropical impressionista de Meyer, a homenagem de Lima exprime um forte conteúdo regionalista. O poeta lamenta não apenas a morte do romancista adorado, mas também o fato de que sua distância o tenha impedido de perceber, na outra ponta do Atlântico, a validade universal de suas próprias ideias. Quanto mais a leitura de Proust seduz esse eu-lírico, mais ele pensa em seu sertão. Pois não foi apenas na Belle Époque parisiense que se percebeu a passagem do tempo, a duração dos sentidos, o contraste entre a aparência social e a interioridade psicológica e as permanências e transformações dos seres. Também no recôndito nordeste brasileiro lograram e padeceram "políticos", "exércitos", "revoluções" e a "nova poesia".

Quem sobrevive ao tempo, o elemento intemporal que unifica o poema é Lampião. Um Lampião que é “eterno" e profundamente polissêmico, ora correspondendo ao cangaceiro, ao herói popular, ao grande mito da identidade regional nordestina; ora se aproximando da lanterna rudimentar, tragada pelo progresso da civilização, mas que segue iluminando, em um gesto de resistência, como farol da memória e do passado. Polissemia similar, diga-se de passagem, àquela da ode de Morand, quando o poeta, através de um arranjo morfológico, na costura entre adjetivo e vocativo, leva a noite "Céleste" a se confundir com a própria figura de Mme Albaret, governanta de Proust.

O motivo regionalista, contudo, não explica todas as possibilidades desse poema. Jorge de Lima, nas palavras de Alfredo Bosi, foi um "poeta em movimento" (p. 183). Em sua obra, 
conviveram surpreendentemente o "poeta parnasiano", o "modernista de cadências regionalistas nordestinas", o "poeta religioso, cristão e bíblico", a "poesia do negro" e, ao final da vida, o "surrealista sui generis, entre barroco e simbolista", da Invenção de Orfeu (BOSI, p. 183). Embora sua produção católica programática seja mais notável durante os anos 30, já no Poema a Marcel Proust as premissas místicas de sua poesia em Cristo parecem tensionar com o veio regionalista nordestino.

Desde o primeiro verso, a prosódia do Poema a Marcel Proust se reveste de uma aura evocatória que a aproxima de uma prece. O poeta conclama a presença do escritor já morto em sua distante terra através de um "ó mon petit / mon petit" que abre e encerra o texto. O oitavo verso, pela insistente repetição de "sertão", torna-se uma litania, uma "continuidade acústica" cujo papel acreditamos ser o de "prolongar no tempo a expressão de uma infinitude" (SPITZER, p. 34). O nome de "Lampião" - em paralelismo com "orações fortes" - também participa dessa mesma continuidade acústica, à qual se somam ainda uma série de prescrições de aspecto litúrgico: “é preciso ver”, “é preciso crer”.Na última estrofe, os traços do programa cristão de Lima tornam-se ainda mais claros. O próprio poeta disse que, após a publicação de seus Poemas escolhidos, passou a sentir-se "insatisfeito" com seus versos e começou a buscar "novas soluções", de "fundo místico" (1958, p. 74). Na realidade, já em Poemas escolhidos essas novas soluções místicas começam a se insinuar. O eu-lírico convida Proust, o homem de "rosto de lua", a abandonar a pecadora vida mundana de Paris - "sai do teu salão" - em favor de uma realidade mais verdadeira, virtuosa e popular onde as sugestões de seu romance, a apologia da arte e da beleza como único caminho de salvação, já encontram amparo desde sempre. A vida sob um outro luar. Não o luar do retrato de Jacques-Émile Blanche, citado por todos até aqui, mas, sim, o "luar como êste do sertão" do Catulo da Paixão Cearense.

Esses hábitos mundanos de Proust são uma preocupação constante de Lima em sua leitura da Recherche. No ensaio Proust, de 1929, ele descreve o romancista como um "Christo, quasi a expirar" (p. 61), vítima de uma "tragedia de sentimento"3, oculta sob a "apparencia decorativa de vida burguesa" (p. 71). Jorge de Lima nunca aceitou no tempo perdido de Proust uma imagem para os dados do conhecimento que a passagem do tempo dissolve, que os sentidos

\footnotetext{
${ }^{3}$ Dois vícios constituem a tragédia sentimental de Proust segundo Jorge de Lima. Primeiro, a homossexualidade: "o homem infantil com tendencias feminis estreitamente pegado à avó, com um 'transfert' identico para a mamãe não soffreu a libertação que a Igreja exerce em todos nós como fonte para a masculinização" (LIMA, 1929, p. 40). Depois, a ascendência judia: "apezar da educação catholica, ficou um indifferente e um amoral, com dois terços da tara judia materna, na physionomia de oriental, na mobilidade judia, na acuidade, na intelligencia, nessa especie de fatalismo israelita tão sensível em toda a sua obra: e até com algumas taras semitas, como a asthma nervosa frequentissima entre os judeus sedentarios" (LIMA, 1929, p. 79-80).
} 
dispersos deixam escapar e que somente a atenção do artista vocacionado, em seu esforço de produzir metáforas, é capaz de recuperar e eternizar. Esse poeta sempre preferiu conceber Proust moralmente, como um "religioso, mystico e crente" (LIMA, 1929, p. 25), um ser "da raça desses inquietos, sempre vizinhos do sobrehumano que é um passo para Deus" (LIMA, 1929, p. 15). Assim, o tempo perdido de Proust é, para Lima, antes de mais nada, um tempo de perdição, do qual o moribundo asmático se redime através da redação de seu livro. Por isso ele sugere que o romancista troque, em um importante jogo de palavras, os salões pelos sertões. Para que, nesse espaço onde o bandido "tira dos ricos para dar aos pobres", onde a beleza natural é ímpar e as orações são fortes, possa melhor compreender suas próprias inclinações artísticas.

Seguimos no nordeste, mas avançamos no tempo. Mais de quatro décadas após a publicação dos Poemas escolhidos de Jorge de Lima, o poeta João Cabral de Melo Neto, uma das penas talvez menos proustianas da literatura brasileira, decidiu também prestar seu tributo à busca do tempo perdido. Ao final de seu Museu de tudo, incluiu dois quartetos nos quais descreve a significação do processo criativo de Proust.

\section{Proust e seu livro}

De certo o sabia, quem viveu com a vida e a obra emaranhadas, que viveu fazendo-as, refazendo-as, elastecendo-a em tempo e páginas, que vestiu sua obra, por dentro, percorrendo-a, viajando em seu barco, de certo viu que um dia acabá-la era matar-se em livro, suicidá-lo.

(NETO, 1975, p. 93)

Dizemos que a pena de João Cabral de Melo Neto é talvez uma das menos proustianas de nossa literatura porque nada parece ser - em aparência - mais distante de sua "poesia do menos", de sua "desconfiança frente ao signo linguístico" e de sua recusa do "transbordamento de significado" (SECCHIN, p. 15) que justamente o "Nilo da linguagem" de Proust, que "transborda nas planícies da verdade, para fertilizá-las" (BENJAMIN, p. 36). E dizemos em aparência porque tampouco isso significa que a única maneira legítima de se suscitar uma reflexão sobre um autor sejam alusões biográficas, apropriações de estilo, aclimatação a 


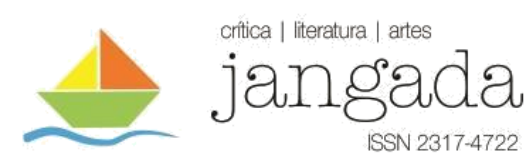

contextos regionais ou adaptação a sistemas específicos de dogmas e crenças. Bem ao contrário, a originalidade de João Cabral de Melo Neto está em representar o processo criativo de Proust através de tudo aquilo que lhe é estranho, retratar um modelo alienando-lhe dessa função.

As superposições de palavras, a confusão polissêmica de classes gramaticais, a abundância de qualificativos, o tom laudatório e grandiloquente que vimos até aqui cede espaço a versos de grande austeridade, dominados por verbos e substantivos. Há apenas um adjetivo nesse poema inteiro - "emaranhados" - e mesmo ele é formado por derivação de um verbo no particípio. Pois não interessa ao eu-lírico cabralino "a vida" sem "a obra"; o "tempo" sem as "páginas”. Aquilo que seduz João Cabral de Melo Neto não são as mãos, "como dois passaros pousados na penumbra", de um "diagramma vivo sepultado na alcova", ou ainda o "rosto de lua", o "rosto de flor noturna" do "quadro bonito de Jacques Emile Blanche", mas, sim, o gênio criativo desse escritor, suas formas de manipulação da linguagem, sua escrita.

Por essa razão João Cabral elege o gerúndio como forma hegemônica do poema. Porque exprime continuidade e sugere a duração de uma atividade. Há, mais além, o próprio significado interno de alguns verbos, como fazer, refazer, elastecer e percorrer, que sugerem o ato de criar e de se exercitar em modo reiterado e duradouro. Mesmo as rimas toantes, presentes ao longo de todo o texto e tão características da poesia de João Cabral, se notabilizam por suas reverberações contínuas dentro de uma mesma frequência sonora. Tudo, enfim, converge para a representação de um labor poético permanente e duradouro.

Secchin nos lembra que o Museu de tudo de João Cabral é uma grande galeria de "retratos", de quadros que apresentam "um rosto humano" (p. 250). Mas essas faces não são retratadas em seus contornos físicos, em sua dimensão moral. Dentro da fortuna cabralina, esse livro é a "obra que mais referencia e reverencia a própria arte"; a representação do homem se faz aqui, acima de tudo, em função do "binômio "criador/criação"” (SECCHIN, p. 250). O poeta pinta o artista em suas ações, em sua prática, em seus modos de abstração do mundo, em seu trabalho. Não é o Proust biográfico que lemos em João Cabral de Melo Neto e, sim, aquele que "vestiu sua obra".

Há teses vultuosas da Recherche contidas nessa poética compacta de João Cabral. A principal delas é a noção de que o indivíduo criador é diferente em natureza do ser social, constitui uma realidade mais profunda e se confunde com a própria obra de arte. Em uma das passagens mais notórias do Temps retrouvé, o narrador proustiano sustenta precisamente que, “para escrever esse livro essencial, o único livro verdadeiro, um grande escritor não precisa, no sentido mais corriqueiro, inventá-lo, uma vez que ele já existe dentro de cada um de nós" (RTP, Jangada | ano 9, nr. 17, jan/jun, 2021 | ISSN 2317-4722 47 | Pá g i n a 


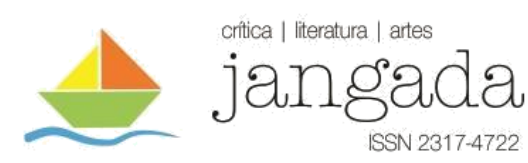

IV, p. 469). Esse é o ideário que João Cabral buscou exprimir no último verso, através de um criativo mecanismo de reversibilidade de pronomes. Como o verdadeiro livro está dentro de nós mesmos, como o grande escritor "vestiu sua obra, por dentro", terminá-lo equivale a encerrar a própria existência do seu criador, condená-los a uma morte recíproca.

Os anos 70 são um momento privilegiado da presença de Proust no Brasil, com várias obras relevantes enraizadas em temas da Recherche. O caso mais conhecido é o Baú de ossos de Pedro Nava, escolhido por Antonio Candido como o livro "mais importante dentre os publicados em 1972" por situar "o gênero autobiográfico nas alturas raras da verdadeira criação" (CANDIDO, 1977, p. 12). Há ainda A Menina do sobrado, de Cyro dos Anjos, que venceu a categoria Memórias do prêmio Jabuti de 1979; e o Labirinto, de Jorge Andrade, publicado em 1978, ao qual o crítico Sábato Magaldi sugere o subtítulo de "em busca do pai perdido" (1978, p. 9). No caso do poema de João Cabral, no entanto, o substrato histórico que nos parece realmente determinante para a formulação de seu poema é o contexto de fortalecimento da crítica genética francesa e a multiplicação dos estudos que elegeram como corpus os manuscritos, cadernos de rascunhos, provas corrigidas, cartas e artigos de jornal redigidos por Marcel Proust.

Posto de outra maneira, a época do poema de João Cabral é aquela em que, graças à aquisição do espólio familiar de Suzy Mante-Proust (1962 e 1977) e da coleção de Jacques Guérin (1983) pelo departamento de manuscritos da Biblioteca Nacional da França, os estudos proustianos passaram a concentrar seus esforços, mais do que nunca, sobre o tempo da criação do romance (FAU, p. 135). Através da decifração de seus tortuosos cadernos, e no objetivo de esclarecer seus complexos métodos de construção do texto, críticos proustianos se lançaram ao desafio de ler a escrita do autor em tempo real. Fundaram até mesmo uma equipe para isso, a Equipe Proust, abrigada até hoje no Instituto de Textos e Manuscritos Modernos (ITEM) da Escola Normal Superior de Paris. João Cabral percebeu que esse não era somente o tempo de Proust; esse era o tempo de Proust e seu livro.

Apenas alguns anos após o poema de João Cabral, um quarto caso de reflexão sobre a Recherche na poesia brasileira retomou essa delicada tensão que a feitura do grande romance sugere entre o eu criativo e sua obra. Em dezembro de 1981, Cláudio Murilo Leal venceu o Prêmio Litrário Nacional de Poesia com a pequena antologia Caderno de Proust, que se abre com um poema intitulado, justamente, Vida e obra:

\section{Vida e obra}

Jangada| ano 9, nr. 17, jan/jun, 2021 | ISSN 2317-4722

48 | P á g in a 
Foi ídolo na minha juventude.

Seu retrato na parede lembra esperanças e sonhos de ser Poeta relegados ao cupim dos incunábulos.

Hoje, desfeitas todas as Rimas, perco-me numa página entre mil, à deriva de dedos desatentos, esquecido de ser alguém e criador.

Aceito, anônimo, a arte de transformar-me no mármore de Brancusi, ovo recém-nado, pássaro, infinito.

A melodia etérea apaga a garganta. Ah! tornar-me Invisível, viver na Obra, ser o Poema, que o resto... se esquece.

(LEAL, 1982, p. 5)

Apesar de seu título, o Caderno de Cláudio Murilo Leal cita Proust em uma única ocasião: um outro poema chamado Notícia proustiana, em que a idílica imagem de "um índio, Peri”, rodeado por "palmeiras e sabiás de Gonçalves Dias", lhe remete involuntariamente à "infância num terreno baldio", ao lado de "todos os seus ídolos", tornando o passado "visível e real" e amortecendo o presente "na ilusão" (p. 12). Para além desse caso solitário, a imagem de Proust se revela sempre de modo alusivo, insinuante, como a referência latente de um esforço de recuperação do passado.

Nunca se fala abertamente dos personagens, do enredo ou da elaboração da Recherche. O tema de sua poesia é outro. Proust e seu romance interessam mais como um contexto que se infiltra e que paira sobre a vida do eu-lírico. O Caderno trata menos de Proust que de um tempo em que seu eu-lírico lia Proust. Um tempo em que Proust - sujeito oculto contextual - é um "ídolo", tem "seu retrato na parede" (novamente o retrato!) e alimenta "esperanças e sonhos de ser Poeta". Um tempo que se viu reduzido melancolicamente ao "cupim dos incunábulos" e que agora se refaz das cinzas como modo de reflexão do fazer poético.

Ao tempo dessas "esperanças e sonhos de ser Poeta", se sucede um outro momento da vida do eu-lírico. Nesse novo tempo, tempo da enunciação, "Rimas", "Obra" e "Poema" (todos maiúsculos, elevados ao estatuto de grandes categorias) já não constituem mais um propósito, um objeto de ambição, mas são vividos subjetivamente, como prolongamento natural da existência. À aspiração de "ser alguém e criador", o eu-lírico passa a preferir "dedos Jangada | ano 9, nr. 17, jan/jun, 2021 | ISSN 2317-4722 


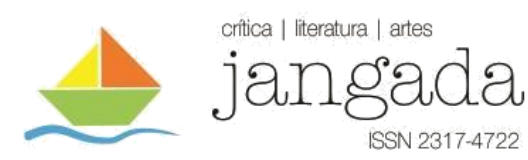

desatentos", ignorantes de todas as rimas, que se deixam levar, se rendem e escrevem "à deriva". A comparação com o minimalista "mármore de Brancusi" exprime exatamente esse desejo de reduzir a forma artificial a uma essência fundamental.

A passagem daquele eu-lírico que tem "esperanças e sonhos de ser Poeta" àquele que tenta - "anônimo" e "invisível" - "viver na Obra, / ser o Poema", percorre um caminho similar ao do narrador da Recherche, que paulatinamente se distancia da admiração mundana pelo escritor Bergotte e se aproxima da consciência de que o "livro essencial, o único livro verdadeiro [...] já existe dentro de cada um de nós" (RTP, IV, p. 469). Mas Cláudio Murilo Leal não partilha da compacta poesia do menos que João Cabral de Melo Neto mobilizou para exprimir essa imagem proustiana de "vida e a obra emaranhadas". Seus versos livres, sem rima ou métrica, incrustados de linguagem coloquial e cotidiana, se filiam à fase consolidada e amadurecida do modernismo, mais interessada em "instaurar uma poesia não poética" que em "seduzir pela pura qualidade verbal" (CANDIDO, 2010, pp. 101 e 115). Seu gesto anônimo, infinito, etéreo e invisível de acolhimento da criação artística ("aceito") lembra a famosa Procura da poesia de Drummond ("não adules o poema. Aceita-o") e extravasa emoções individuais com grande naturalidade e tom prosaico.

Há uma espécie de gesto de resistência nesse retorno de Cláudio Murilo Leal aos versos livres e brancos dos anos 40. O Caderno de Proust é publicado e premiado no auge da poesia marginal brasileira, em contexto no qual ainda exerciam grande protagonismo movimentos de vanguarda como o concretismo e a tropicália. Sua poesia não poética, voltada para uma recuperação singela, clara e despretensiosa de imagens que se impregnaram na memória ("ovo recém-nado" é a única exceção mais ousada e hermética do poema) contrasta com o esforço de renovação da linguagem, de desarticulação da gramática normativa e de subversão da unidade rítmica-formal de vários poetas contemporâneos. Cite-se Armando Freitas Filho, Ana Cristina Cesar, Paulo Leminski ou ainda os irmãos Campos, apenas para ficarmos com alguns exemplos.

Essa situação não é de todo inédita. O romance já havia manifestado esse gesto de resistência uma década antes do Caderno de Proust com o início da publicação das Memórias de Pedro Nava - elas mesmas profundamente impregnadas da Recherche de Proust. Antagonizando com as diversas correntes de vanguarda de seu tempo, o escritor mineiro já antecipava o "mecanismo de defesa" e o desejo de "preservar os seus elementos discursivos e o seu direito a uma sintaxe regular" (CANDIDO, 1977, p. 13) que leríamos algum tempo depois na poesia de Cláudio Murilo Leal. 


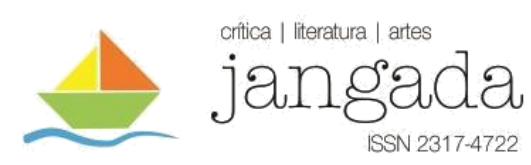

O romance foi o espaço prioritário da presença de Proust na literatura brasileira, sobretudo após as importantes experiências não apenas de Nava, mas também de Cyro dos Anjos, Jorge Andrade, Otacílio Alecrim ou ainda dos próprios Augusto Meyer e Jorge de Lima que há pouco líamos. Mas esse breve quadro de poemas mostra que a ressonância do autor no país não se limitou a esse gênero. Fez-se presente também na lírica e nela deu provas de notável diversidade temática e formal. As mais distintas correntes artísticas - não raro antagônicas entre si - se enraizaram no substrato comum da Recherche, o que apenas ressalta o importante papel desempenhado por esse romance no empenho moderno brasileiro de assimilação original de suas matrizes culturais.

No primeiro modernismo, aquele de Augusto Meyer, nos deparamos com um eu-lírico que contempla o romance proustiano de longe, refletindo-o com grande delicadeza e finura em um cotidiano indolente nos pampas gaúchos. Também Jorge de Lima lerá Proust sob a óptica de sua realidade imediata, mas em sentido diametralmente oposto. Embebido do regionalismo nordestino, ele exalta sua cultura local e lamenta que o narrador proustiano - embora vetor de ideias de grande universalidade - tenha se confinado no universo mundano parisiense da virada do século. João Cabral de Melo Neto - que, pela profunda compressão da linguagem, pela máxima concentração de significado, ninguém ousaria chamar um proustiano - surpreende ao eleger como tema a barroca engenharia da Recherche e se interessa pela ideia tão central nesse livro de que a obra de arte seja uma verdadeira extensão do ser criativo. Uma extensão ou prolongamento que também fascina Cláudio Murilo Leal, mas que se exprime através de versos livres de estilo drummondiano, sob a forma de um amadurecimento da consciência artística e da passagem do tempo de seu eu-lírico. São quatro maneiras distintas de se ler um mesmo livro; quatro maneiras distintas de a poesia abordar um romance; quatro maneiras distintas de o local assimilar o estrangeiro; quatro maneiras distintas, enfim, pelas quais Proust intervém na elaboração da moderna literatura brasileira e é reciprocamente compreendido por ela.

\section{REFERÊNCIAS BIBLIOGRÁFICAS}

BOSI, Alfredo. Jorge de Lima poeta em movimento (Do "menino impossível" ao Livro de sonetos). In: Estudos Avançados, São Paulo, v. 30, n. 86, p. 183-207, 2016.ANDIDO, Antonio. A Literatura brasileira em 1972. In: Revista Iberoamericana, Pittsburgh, v. 43, n. 98-99, pp. 5$16,1977$.

CANDIDO, Antonio. Iniciação à literatura brasileira. Rio de Janeiro: Ouro sobre Azul, 2010. CARVALHAL, Tania Franco. Autobiographical writing in Brazil - The 'Proustians' Jorge de Lima, Augusto Meyer, and Pedro Nava. In: MILLER, J. Scott \& SONDRUP, Steven P. The I 


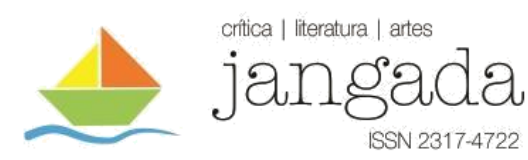

of the beholder - A Prolegomenon to the Intercultural study of self. Provo: ICLA Intercultural Studies Comittee, 2002, p. 95-108.

COMPAGNON, Antoine. Paul Morand et la princesse Soutzo. In: TADIÉ, Jean-Yves (org.). Proust et ses amis. Paris: Gallimard, 2010

FAU, Guillaume. Le fonds Proust au département des Manuscrits de la Bibliothèque nationale de France: notes pour un cinquantenaire. Genesis, Paris, n. 36, p. 135-140, 2013

GALVÃO, Walnice Nogueira. Em busca de um tempo perdido. In: WILLEMART, Philippe. Educação sentimental em Proust. São Paulo: Ateliê Editorial, 2002.

LEAL, Cláudio Murilo. Caderno de Proust. Rio de Janeiro: José Olympio, 1982.

LIMA, Jorge de. Obra completa. Rio de Janeiro: José Aguilar, organização de Afrânio Coutinho, vol. I, 1958.

LIMA, Jorge de. Proust. In: Dois ensaios. Maceió: Casa Ramalho, 1929.

MAGALDI, Sábato. Prefácio. In: ANDRADE, Jorge. Labirinto. São Paulo: Paz e Terra, 1978.MEYER, Augusto. Giraluz. Porto Alegre: Livraria do Globo, 1928.

MORAND, Paul. Lampes à arc: avec un dessin de l'auteur. Paris: Au sans pareil, 1920.

MORAND, Paul. Le visiteur du soir. Genebra: La Palatine, 1949

MORAND, Paul. Ode à Marcel Proust. In: COELHO, Saldanha (org.). Homenagem a Proust. Rio de Janeiro: Revista Branca, n. 4, trad. Carlos Drummond de Andrade, 1948, p. 5-6.

NETO, João Cabral de Melo. Museu de tudo. Rio de Janeiro: Livraria José Olympio Editora, 1975.

ROCHA, Tadeu. Modernismo e Regionalismo. Maceió: Imprensa Oficial de Alagoas, 1964.

SAUTHIER, Étienne. Combray sous les tropiques : diffusions, réceptions, appropriations et traductions de l'œuvre de Marcel Proust au Brésil (1913-1960). Tese (Doutorado em História) - Universidade de Paris III - Sorbonne Nouvelle. Paris, 2014.

SECCHIN, Antonio Carlos. João Cabral: a poesia do menos. Rio de Janeiro: Topbooks, 1999. SPITZER, Leo. La enumeración caótica en la poesia moderna. Buenos Aires: Instituto de Filología de la Facultad de Filosofía y Letras de la Universidad de Buenos Aires, 1945.

TADIÉ, Jean-Yves. Marcel Proust. Paris: Gallimard, Folio, vols. I e II, 1996. 